\title{
Generation of transgenic rice with reduced content of major and novel high molecular weight allergens
}

\author{
Yuko Ogo ${ }^{1}$, Yuhya Wakasa', Kana Hirano ${ }^{2}$, Atsuo Urisu ${ }^{3}$, Tsukasa Matsuda ${ }^{2}$ and Fumio Takaiwa ${ }^{\text {* }}$
}

\begin{abstract}
Background: Rice seed proteins contain antigens that provoke allergic responses in some individuals with food allergy, particularly in those with cereal allergy, and these antigens can elicit clinical symptoms such as eczema and dermatitis. We previously generated transgenic rice with reduced accumulation of the three major allergens, which dramatically reduced the level of IgE binding from patients' sera. However, the transgenic rice still possesses allergenic reactivity. Recently, two globulin-like proteins were identified as candidates of novel high molecular weight (HMW) lgE-binding proteins that cause rice allergy.

Results: We identified a glucosidase family encoded by four genes as novel HMW rice allergens based on IgE antibody reactivity from individuals with allergy to rice. To further reduce allergenicity, we generated transgenic rice with reduced accumulation of these HMW allergens. We crossed the rice with reduced HMW allergens and with reduced major allergens, and all major and HMW allergens were substantially reduced in the progeny of the crossed rice. Allergen suppression did not significantly alter accumulation patterns of seed storage proteins and protein folding enzymes. The sera of a portion of patients showed low lgE-binding to the crossed line, suggesting that the crossed line is effective for a portion of patients who are allergic to proteins other than major allergens.
\end{abstract}

Conclusions: The transgenic rice with reduced levels of all major and HMW allergens is thought to be an option for a portion of allergy patients with hypersensitive responses to various kinds of rice allergens.

Keywords: Food allergy; IgE antibody; Oryza sativa L; RNAi; Transgenic rice

\section{Background}

Rice is a major cereal food consumed by more than half of the world population. The prevalence of IgE-mediated rice allergy is approximately $10 \%$ in atopic subjects. Symptoms of rice allergy include atopic dermatitis, eczema, and foodprotein-induced enterocolitis syndrome (Hoffman 1975; Shibasaki et al., 1979; Ikezawa et al., 1992; Sicherer et al. 1998; Uchio et al., 1998; Mehr et al., 2009). Multiple rice seed proteins are responsible for rice allergy (Urisu et al., 1991). Among them, $\alpha$-globulin $(26 \mathrm{kDa}), \beta$-glyoxalase I (33 kDa), and $\alpha$-amylase/trypsin inhibitor (14-16 kDa) were identified as major rice allergens based on recognition by IgE from individuals with food allergy (Alvarez et al., 1995; Limas et al., 1990; Usui et al., 2001; Matsuda et al.,

\footnotetext{
* Correspondence: takaiwa@affrc.go.jp

${ }^{1}$ Transgenic Crop Research and Development Center, National Institute of Agrobiological Sciences, Kannondai 3-1-3, Tsukuba, Ibaraki 305-8604, Japan Full list of author information is available at the end of the article
}

2006). The 14-16 kDa $\alpha$-amylase/trypsin inhibitors constitute a multigene family, whereas the 26 and $33 \mathrm{kDa}$ allergens are encoded by single-copy genes. These allergens strongly react with IgE antibody in sera from many individuals with rice allergy, and caused eczematous and atopic dermatitis (Urisu et al., 1991).

Avoidance of food containing allergens is one of the most important therapeutic strategies for those with food allergy. Allergens have been removed from rice by several processing technologies such as enzymatic digestion, alkaline hydrolysis, and high hydrostatic pressure (Watanabe et al., 1990a, 1990b; Kato et al., 2000). Some of these processes have been commercialized to produce low-allergen rice in Japan; however, the taste quality of processed rice is reduced by these chemical, enzymatic, or physical treatments, and the treatments are costly. Therefore, it is important to develop a cost-effective means to produce low-allergen (hypo-allergenic) rice with good taste. We 
previously generated hypo-allergenic transgenic rice, in which the levels of major seed allergen genes $(26 \mathrm{kDa}$, $33 \mathrm{kDa}$, and $14-16 \mathrm{kDa}$ allergens) were suppressed (Wakasa et al., 2011a). To suppress the major allergen levels in rice grains, we first found a mutant in the Koshihikari background that lacked the $26 \mathrm{kDa}$ allergen (GbN-1). Then, $33 \mathrm{kDa}$ and 14-16 kDa allergen levels were suppressed by RNA interference (RNAi) using GbN-1 as a host rice. In the transgenic line, the content of the three major allergens was remarkably reduced to a very faint level. IgE binding of patients' sera to the transgenic rice seed with reduced levels of major allergens was substantially lower compared with that of non-transgenic (NT) Koshihikari (Wakasa et al., 2011a). However, some individuals retained allergenic reactivity to the transgenic rice. These results indicate that additional allergens are present in rice, which must be removed for the optimum health of individuals with a wide variety of allergies to rice.

Several major rice allergens were identified in previous studies. Urisu et al. (1991) showed that IgE from patients with rice allergy detected several allergenic proteins with high molecular weight (HMW), which have not yet been identified. Two globulin-like proteins of $52 \mathrm{kDa}$ and $63 \mathrm{kDa}$, which correspond to the HMW allergenic proteins, have recently been identified as novel IgE-binding proteins. These globulin-like proteins are candidates for rice allergens based on recognition by IgE from patients with rice allergy (Satoh et al., 2011). The $52 \mathrm{kDa}$ and $63 \mathrm{kDa}$ proteins are strongly expressed in rice seed, and are thought to be major causes of rice allergy. Here, we identified a multigene glucosidase family as novel IgEbinding HMW proteins, which are also candidates for rice allergens. We suppressed the levels of these HMW allergens by RNAi and crossed the RNAi rice with the transgenic rice with reduced levels of the major allergens.
The allergen-reduced transgenic rice is a promising candidate for generating hypo-allergenic rice.

\section{Results and discussion}

\section{Identification of HMW rice allergens}

To identify HMW candidate proteins for rice allergens that have not been previously analyzed, we performed western blot with serum IgE from 24 rice-positive patients using gels with low acrylamide concentrations. The albumin-globulin rice extract was subjected to $1 \mathrm{D}$ SDS-PAGE. Two proteins of approximately $90 \mathrm{kDa}$ and $55 \mathrm{kDa}$, which were reactive to IgE from several patients with rice allergy (Urisu et al., 1999), were detected (Figure 1). These proteins were not detected with the control sera. To identify these proteins, the two bands were cut from Coomassie brilliant blue-stained gels, in-gel digested with trypsin, and subjected to protein identification by MALDITOF-MS/MS. The $90 \mathrm{kDa}$ protein was identified as an $\alpha$-glucosidase (ONG1; Os06g0675700) (Table 1). Database searches identified two ONG1 homologs, ONG2\&3 (Os06g0676700) and ONG4 (Os01g0130400), whose amino acid similarities to ONG1 are $97 \%$ and $90 \%$, respectively. ONG1, ONG2\&3, and ONG4 were reported as proteins extracted from rice seeds (Nakai et al., 2007). The $55 \mathrm{kDa}$ protein was identified as protein disulfide isomerase (PDI) 1 (OsPDIL1;1; Os11g0199200) (Table 1). PDI is essential for protein folding in the ER lumen, and is involved in catalysis of disulfide bond formation (reduction or isomerization) and in assisting polypeptide folding (Wilkinson and Gilbert, 2004; Gruber et al., 2006). Rice contains 19 PDIlike genes (Houston et al., 2005), and OsPDIL1; 1 is one of the major rice PDI proteins. Failure to express OsPDIL1;1 in rice results in a floury endosperm and an endoplasmic reticulum stress response in rice (Satoh-Cruz et al., 2010; Han et al., 2012).

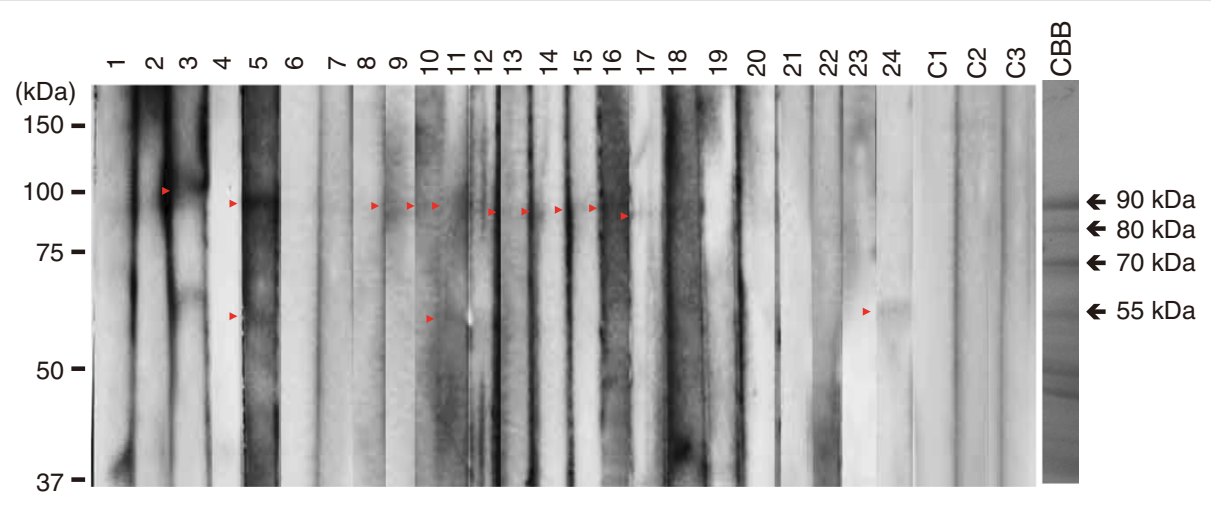

Figure 1 Western blotting of albumin-globulin fraction protein using sera of patients with rice allergy. Lanes 1 to 24 , sera from patients; Lanes C1 to C3, sera from healthy volunteers. Red arrow heads indicate positive bands detected by sera. Bands indicated by arrows ( $90 \mathrm{kDa}$ and $55 \mathrm{kDa}$ ) are the proteins subjected to peptide identification by MALDI-TOF MS/MS. 
Table 1 Identification of IgE-binding rice proteins by MALDI-TOF MS/MS

\begin{tabular}{llllllll}
\hline Name & Locus ID & MW (kDa) & MS & & \multicolumn{2}{l}{ MS/MS } \\
& & & Sequence coverage (\%) & Matched peptide & & Sequence coverage (\%) & Matched peptide \\
\hline ONG1 & Os06g0675700 & 90 & 27 & 15 & 14 & 7 \\
OsPDIL1;1 & Os11g0199200 & 55 & 23 & 12 & 10 & 4 \\
\hline
\end{tabular}

\section{Generation of transgenic rice with reduced levels of the HMW allergens}

To reduce rice allergenicity, we suppress the HMW allergens identified above using RNAi. However, OsPDIL1; 1 plays an important role in seed storage protein accumulation, and knockdown of OsPDIL1; 1 severely disrupts seed quality. OsPDIL1; 1 was not selected for suppression in the present experiment. ONG1 was selected for suppression, because no studies have reported that ONG knockdown significantly affects seed quality. In addition to ONG1, we suppressed ONG2\&3 and ONG4 because they are highly homologous to ONG1 and accumulate in seeds. Satoh et al. (2011) recently identified two globulin-like proteins of $52 \mathrm{kDa}$ and $63 \mathrm{kDa}$ as HMW IgE-binding proteins that are candidates for rice allergens. In this study, we also suppress the $52 \mathrm{kDa}$ and $63 \mathrm{kDa}$ globulins by RNAi. The $63 \mathrm{kDa}$ globulin, ONG2\&3, and ONG4 are expressed in embryo and endosperm, whereas the $52 \mathrm{kDa}$ globulin and ONG1 are expressed primarily in endosperm (Additional file 1: Figure S1). We use several endospermspecific promoters, which confer expression throughout the whole endosperm, and $18 \mathrm{kDa}$ oleosin promoter, which confers embryo- and endosperm-specific expression but does not confer expression at the inner side of endosperm. To generate transgenic rice in which the HMW allergens were strongly suppressed throughout the endosperm, we used the endosperm-specific promoters (13 kDa prolamin, glutelin $B-1$, and $16 \mathrm{kDa}$ prolamin promoters) to express RNAi constructs of the HMW allergens. To prevent possible contamination of the HMW allergens from embryo, we used the $18 \mathrm{kDa}$ oleosin promoter to express RNAi constructs of the HMW allergens (Figure 2). A mutated acetolactate synthase gene (mALS) under callus-specific promoter (CSP) was used as a selectable marker gene, which was acceptable for commercial cultivation because they were derived from the rice genome and selection was restricted to the callus stage. These binary vectors were introduced into Koshihikari, which is the most popular cultivated elite variety in Japan due to its excellent taste. We generated 30 transgenic lines with endosperm-specific suppression, and endosperm- and embryo-specific suppression of the HMW allergens each.

\section{Western blot of $52 \mathrm{kDa}$ and $63 \mathrm{kDa}$ globulins}

We generated antibodies against the $52 \mathrm{kDa}$ and $63 \mathrm{kDa}$ globulins and investigated protein expression patterns by western blotting. Protein was extracted from mature seeds without embryos of transgenic rice with endospermspecific suppression of the HMW allergens. Both $52 \mathrm{kDa}$ and $63 \mathrm{kDa}$ globulins were strongly repressed in endosperm from several lines (Figure 3A). Protein was extracted from mature seeds including embryos of transgenic rice with endosperm- and embryo-specific suppression of the HMW allergens. Both $52 \mathrm{kDa}$ and $63 \mathrm{kDa}$ globulins were suppressed in whole seeds including embryos in several lines (Figure 3B). The RNAi constructs driven by the $18 \mathrm{kDa}$ oleosin promoter substantially suppressed $52 \mathrm{kDa}$ and $63 \mathrm{kDa}$ globulins in whole seeds. We used transgenic rice with endosperm- and embryo-specific suppression of the HMW allergens for further studies.

\section{Real-time PCR of ONG1, ONG2\&3, and ONG4}

We attempted to generate antibodies against ONG1, ONG2\&3, and ONG4; however, strongly reactive antibodies to ONGs were not produced. Therefore, mRNA expression of ONG1, ONG2E3, and ONG4 in transgenic rice seeds was investigated by real-time PCR. We extracted total RNA from transgenic rice seeds with endospermand embryo-specific suppression of the HMW allergens and performed real-time PCR. The mRNA levels of ONG1, ONG2E3, and ONG4 were substantially reduced in a few

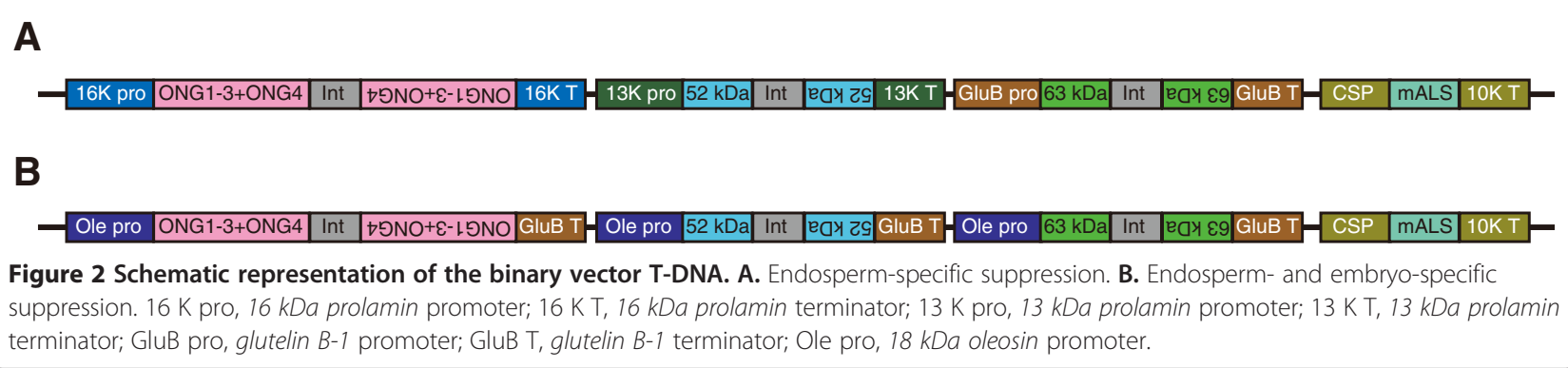


A

C
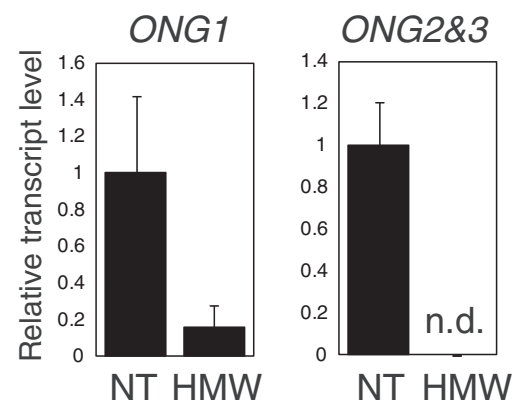

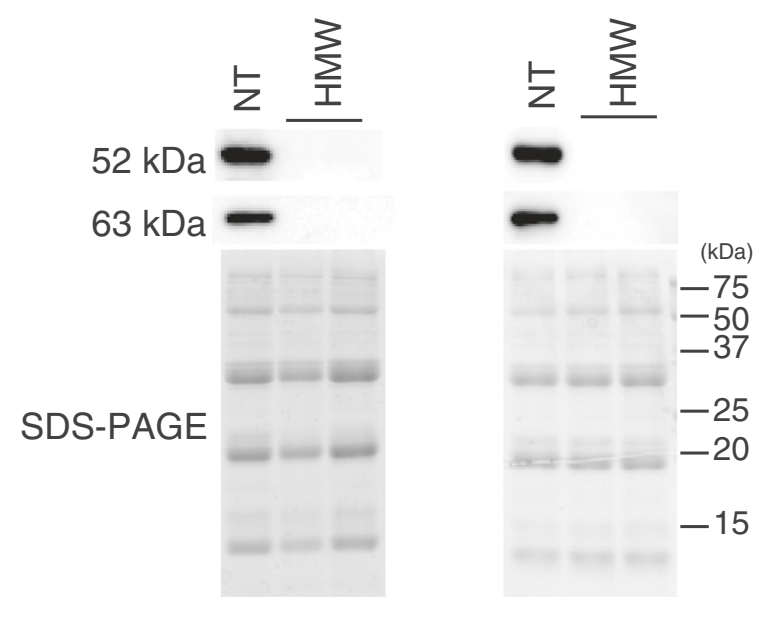

B

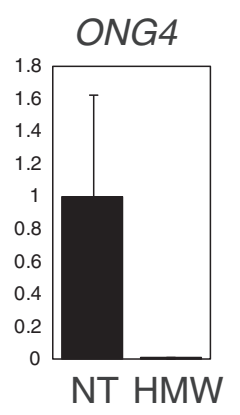

Figure 3 Generation of rice lines with reduced levels of the HMW allergens. A. Western blot of $52 \mathrm{kDa}$ and $63 \mathrm{kDa}$ globulins in transgenic rice with endosperm-specific suppression of the HMW allergens. B. Western blot of $52 \mathrm{kDa}$ and $63 \mathrm{kDa}$ globulins in transgenic rice with endosperm- and embryo-specific suppression of the HMW allergens. C. Real-time PCR of ONG1, ONG2\&3, and ONG4 using transgenic rice with endosperm- and embryo-specific suppression of the HMW allergens. NT, non-transgenic Koshihikari; HMW, transgenic rice with reduced levels of the HMW allergens.

lines (Figure 3C). According to the Western blot of $52 \mathrm{kDa}$ and $63 \mathrm{kDa}$ globulins and real-time PCR of ONGs, we identified a line in which the levels of $52 \mathrm{kDa}$ globulin, $63 \mathrm{kDa}$ globulin, ONG1, ONG2E3, and ONG4 were substantially suppressed in endosperm and embryo.

\section{Crossing transgenic rice lines with reduced levels of major and HMW allergens}

We crossed transgenic rice lines with reduced levels of the HMW allergens in endosperm and embryo, and transgenic lines with reduced levels of the major allergens. In the lines with reduced levels of the major allergens, the $33 \mathrm{kDa}$ and the 14-16 kDa protein were suppressed by RNAi, whereas the $26 \mathrm{kDa}$ protein was knocked out by $\gamma$ ray irradiation mutagenesis (Iida et al., 1998; Wakasa et al., 2011). Suppression of the $26 \mathrm{kDa}$ protein was only observed in the recessive homozygote of the GbN-1 mutation; therefore, $F_{2}$ seeds were analyzed. The $F_{2}$ seeds were cut in half, and protein was extracted from the half without the embryo. The $26 \mathrm{kDa}$ protein was suppressed in 90 of $397 \mathrm{~F}_{2}$ seeds (23\% of the total seeds), and the $52 \mathrm{kDa}$ globulin was suppressed in 220 of $397 \mathrm{~F}_{2}$ seeds (55\% of the total seeds) (Table 2). We identified 55 of $397 \mathrm{~F}_{2}$ seeds (14\% of the total seeds) in which both the $26 \mathrm{kDa}$ and the $52 \mathrm{kDa}$ proteins were suppressed. Of these $55 \mathrm{~F}_{2}$ seeds, the $33 \mathrm{kDa}$, the $14-16 \mathrm{kDa}$, and the $63 \mathrm{kDa}$ protein levels were substantially suppressed in 32 , 32, and $48 \mathrm{~F}_{2}$ seeds, respectively. We identified $24 \mathrm{~F}_{2}$ seeds ( $6 \%$ of the total seeds) in which the $26 \mathrm{kDa}$, the $33 \mathrm{kDa}$, the $14-16 \mathrm{kDa}$, the $52 \mathrm{kDa}$, and the $63 \mathrm{kDa}$ protein levels were substantially suppressed (Table 2).

The remaining $F_{2}$ seed halves containing embryos were grown and $F_{3}$ seeds were harvested. We obtained several $\mathrm{F}_{3}$ lines in which the $26 \mathrm{kDa}$, the $33 \mathrm{kDa}$, the $14-16 \mathrm{kDa}$, the $52 \mathrm{kDa}$, and the $63 \mathrm{kDa}$ allergen levels were substantially suppressed (Figure 4A). Total RNA was extracted from these $\mathrm{F}_{3}$ seeds and real-time PCR of ONG genes was performed. We identified $\mathrm{F}_{3}$ seeds in which expression of ONG1, ONG2E3, and ONG4 was substantially suppressed. We obtained a few $\mathrm{F}_{3}$ lines in which the contents of all major and HMW allergens were reduced. These lines were named as Major $\mathrm{x}$ HMW rice.

\section{Allergenic potential of the rice lines with reduced levels of the major and HMW allergens}

In the previous study, IgE binding of protein extracts from the line with reduced levels of the three major allergens was analyzed by immuno-dot-blotting analysis with sera from 15 patients (Wakasa et al., 2011a). The results

Table 2 Target gene suppression efficiency in transgenic rice lines

\begin{tabular}{|c|c|c|c|c|c|c|c|c|}
\hline & \multirow[t]{2}{*}{ Total F2 seed } & \multirow[t]{2}{*}{26 kDa } & \multirow[t]{2}{*}{52 kDa } & \multirow[t]{2}{*}{$26 \& 52 \mathrm{kDa}$} & \multicolumn{3}{|c|}{$\begin{array}{l}\text { Among both } 26 \mathrm{kDa} \text { and } 52 \mathrm{kDa} \\
\text { suppressed seeds, }\end{array}$} & \multirow[t]{2}{*}{ All } \\
\hline & & & & & 33 kDa & 14-16 kDa & $63 \mathrm{kDa}$ & \\
\hline $\begin{array}{l}\text { Number/investigated } \\
\text { seeds }\end{array}$ & 397 & 90/397 & $220 / 397$ & $55 / 397$ & $32 / 55$ & $32 / 55$ & $48 / 55$ & $24 / 397$ \\
\hline$\%$ & 100 & 23 & 55 & 14 & - & - & - & 6 \\
\hline
\end{tabular}

$\%$ indicates percentage of the seed number to the total $F_{2}$ seed number (397). $26 \mathrm{kDa}, 52 \mathrm{kDa}$, and 26 \& $52 \mathrm{kDa}$ indicate the number of the transgenic seeds with reduced level of the $26 \mathrm{kDa}$, the $52 \mathrm{kDa}$, and both the $26 \mathrm{kDa}$ and the $52 \mathrm{kDa}$ allergens, respectively. $33 \mathrm{kDa}, 14-16 \mathrm{kDa}$ and $63 \mathrm{kDa}$ indicate the number of the seeds with reduced levels of the $33 \mathrm{kDa}$, the 14-16 kDa and the $63 \mathrm{kDa}$ allergens, respectively, among the transgenic seeds with reduced levels of both the $26 \mathrm{kDa}$ and the $52 \mathrm{kDa}$ allergens ( 55 seeds). All indicates the number of transgenic seeds with reduced levels of all the major and the HMW allergens. 


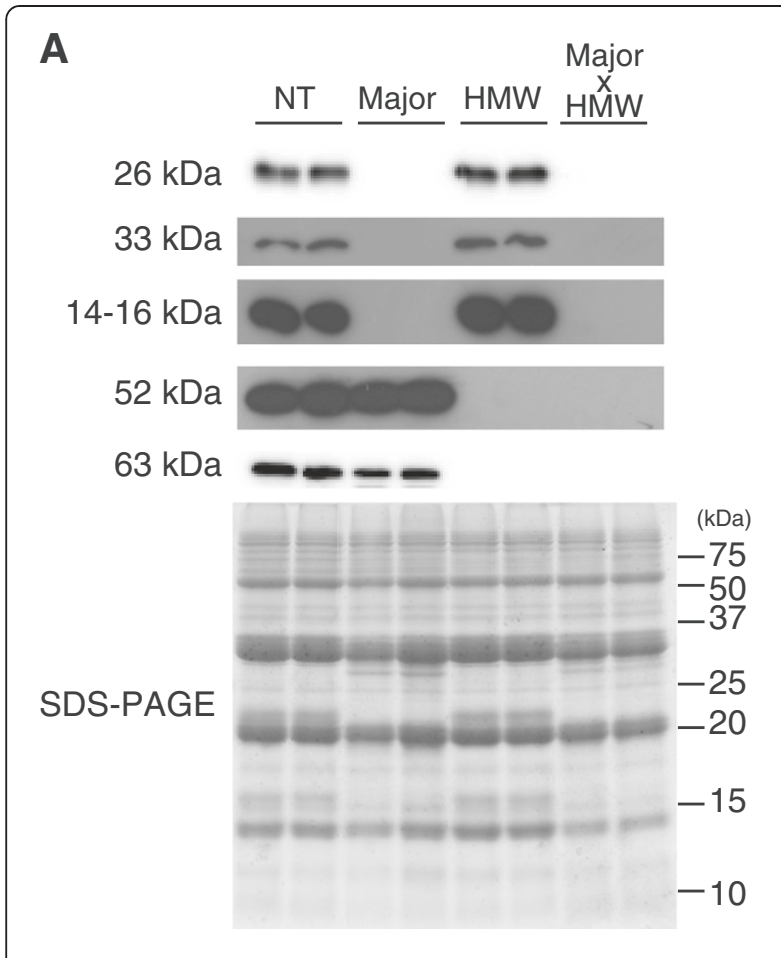

B
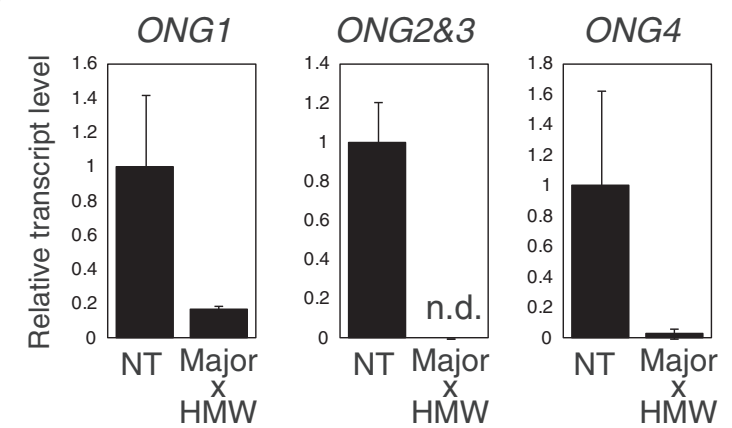

Figure 4 Crossing of transgenic rice lines with reduced levels of the major and the HMW allergens. A. Western blot of the major allergens (26 kDa, $33 \mathrm{kDa}$, and 14-16 kDa) and the HMW allergens (52 kDa and $63 \mathrm{kDa}$ allergens). B. Real-time PCR of ONG1, ONG2\&3, and ONG4. NT, non-transgenic Koshihikari; Major, the rice lines with reduced levels of major allergens; HMW, the rice lines with reduced levels of the HMW allergens (endosperm- and embryo-specific suppression); Major $x$ HMW, the rice lines with reduced levels of the major and the HMW allergens.

showed that IgE reactivity of sera from 9 patients was dramatically reduced ( $>90 \%$ ), whereas that of 5 patients was not substantially decreased, suggesting that a significant number of patients were allergic to proteins other than the three major allergens. Major $\mathrm{x} H \mathrm{HMW}$ rice may be an option for allergy patients with hypersensitive responses to various kinds of rice allergens. To estimate allergenic potential of the rice seeds of these lines, IgE binding of seed protein extracts from two Major $\mathrm{x}$ HMW lines was analyzed using immuno-dot blotting using serum specimens from 10 allergic patients with relatively high levels of serum IgE to rice seed proteins. Typical IgE dot-blotting images of four representative serum specimens are shown in Figure 5. Only two serum specimens including serum 2 showed lower IgE-binding to Major $\mathrm{x}$ HMW lines than to the lines with reduced contents of the major allergens, while the others showed IgE binding to Major x HMW lines almost equally to the Major lines or tended to give even slightly high IgE-binding (Figure 5). These results suggested that Major $\mathrm{x}$ HMW rice is effective for a portion of the patients who are allergic to proteins other than major allergens, although it may not be effective for the other patients. Thus, future practical utilization of the hypoallergenic Major x HMW lines would become more effective in combination with personal clinical tests for patients' serum IgE specificity to rice allergen components.

\section{Seed characteristics in rice lines with reduced levels of the major and HMW allergens}

We investigated the accumulation of seed storage proteins in mature seeds. In transgenic rice lines with reduced levels of the major allergens, with reduced levels of the HMW allergens, and with reduced levels of both the major and the HMW allergens, glutelins (GluA, GluB, GluC) and prolamins (RM1, RM2, RM4, RM9, $16 \mathrm{kDa}$ prolamin, $10 \mathrm{kDa}$ prolamin) accumulated to the same levels as observed in NT Koshihikari (Figure 6A). Reduction of the major and the HMW allergen levels did not significantly alter the accumulation of most seed storage proteins, which may be explained by the low expression level of these allergens $(<5 \%$ by weight of total seed proteins). There was no significant difference in the amounts of OsBiP1, OsPDIL1; 1 and calnexin among NT Koshihikari and transgenic rice lines (Figure 6A). OsBiP1, OsPDIL1; 1 and calnexin levels are sensitive to perturbations of the protein folding and transport system in the ER lumen (Oono et al., 2010; Wakasa et al., 2011b). However, the observation that OsBiP1, OsPDIL1; 1 and calnexin protein levels did not significantly differ among all lines suggests that the ER protein folding and transport system was not disrupted in the transgenic rice seed cells.

The seed morphology of the transgenic lines was investigated (Figure 6B). No significant difference in seed length, seed thickness, and protein content were observed among all lines (Table 3 ). The seed weights of the lines with reduced levels of the major allergens and Major x HMW lines were 14-15 mg/seed, whereas that of NT Koshihikari and the lines with reduced levels of the HMW allergens were 17-18 mg/seed (Table 3). Seed width of the lines with reduced levels of the major allergens and Major x HMW lines was less than those of NT Koshihikari and the lines with reduced levels of the HMW allergens (Table 3). The reduction of seed weight 
and seed width is thought to be inherited from GbN-1. Wakasa et al. (2011a) reported that seed weights of GbN-1 and the lines with reduced levels of the major allergens were slightly lower than NT Koshihikari. GbN-1 is sensitive to adverse conditions and shows reduced growth, yield, and seed weight under unfavorable conditions (unpublished data). Conversely, GbN-1 growth is not delayed and the seeds are maintained in good quality with favorable conditions such as a large field and good insolation conditions. In the present study, the lines with reduced levels of the major allergens and Major x HMW lines showed strong GbN-1 characteristics because rice
A

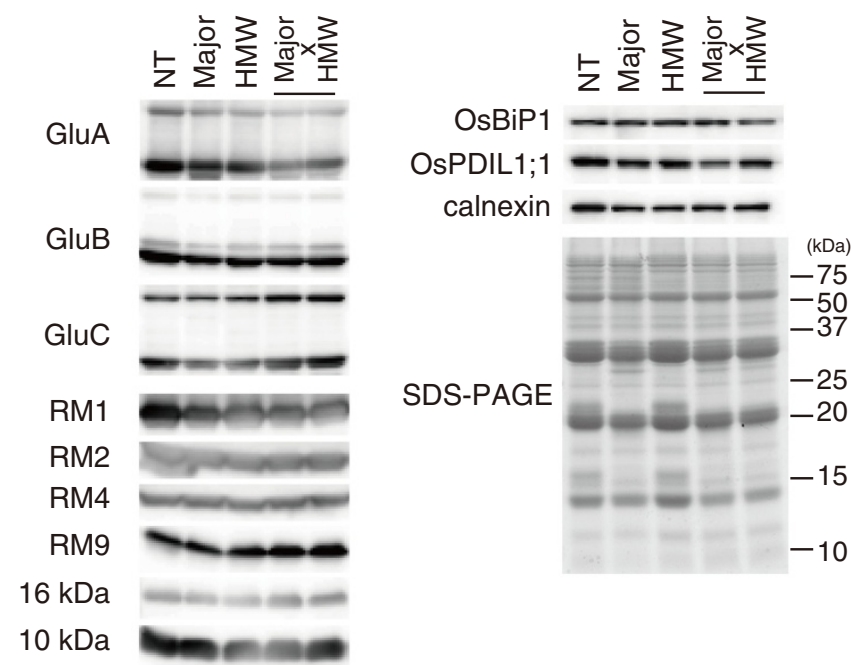

B

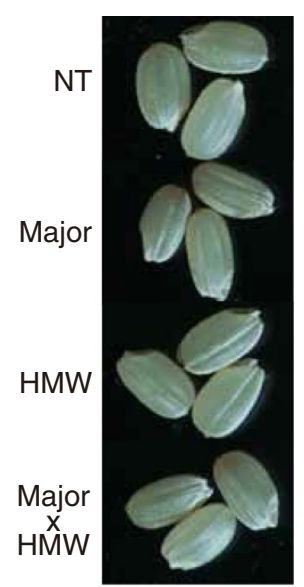

Figure $\mathbf{6}$ Characterization of rice lines with reduced levels of the major and the HMW allergens. A. Western blot of seed storage proteins and proteins involved in protein folding. B. Seed phenotype. NT, non-transgenic Koshihikari; Major, the rice lines with reduced levels of the major allergens; HMW, the rice lines with reduced levels of the HMW allergens (endosperm and embryo-specific suppression); Major $\mathrm{x}$ HMW, the rice lines with reduced levels of the major and the HMW allergens. 
Table 3 Seed characteristics in the transgenic rice lines

\begin{tabular}{llllll}
\hline Name & Length $(\mathbf{m m})$ & Width $(\mathbf{m m})$ & Thickness $(\mathbf{m m})$ & Weight $(\mathbf{m g} /$ seed) & Protein content (\%) \\
\hline NT & $4.71 \pm 0.24$ & $2.65 \pm 0.09$ & $1.84 \pm 0.04$ & $17.9 \pm 0.5$ & $13.5 \pm 0.6$ \\
Major & $4.65 \pm 0.18$ & $2.27 \pm 0.30$ & $1.75 \pm 0.09$ & $14.0 \pm 0.7$ & $14.9 \pm 0.9$ \\
HMW & $4.68 \pm 0.08$ & $2.68 \pm 0.11$ & $1.78 \pm 0.05$ & $16.9 \pm 0.6$ & $13.6 \pm 1.2$ \\
Major $\times$ HMW & $4.75 \pm 0.21$ & $2.44 \pm 0.20$ & $1.78 \pm 0.04$ & $15.0 \pm 0.6$ & $14.5 \pm 1.3$ \\
\hline
\end{tabular}

Seed length, width, thickness, and weight, $n=8$; total protein content, $n=3$. Values represent means \pm standard deviation. NT, non-transgenic Koshihikari; Major, the rice lines with reduced levels of the major allergens; HMW, the rice lines with reduced levels of the HMW allergens (endosperm and embryo-specific suppression); Major x HMW, the rice lines with reduced levels of the major and the HMW allergens.

plants were grown in small pots, in which rice could not set their roots deep enough. Backcross to NT Kosihikari is effective to diminish these undesirable GbN-1 phenotypes and improve the seed quality of Major $\mathrm{x} H \mathrm{HMW}$ lines.

Once the safety evaluation of the transgenic rice is performed, Major x HMW lines can be utilized by individuals with a rice allergy whose serum IgE recognizes these allergens. The transgenic rice approach has several advantages over conventional hypo-allergenic rice produced by processing with enzymatic and physical treatments. Our hypo-allergenic rice was generated using the highly edible Koshihikari variety, and the transgenic product is cost-effective. The seed quality of Major x HMW lines can be improved by backcrossing with Koshihikari. Major x HMW lines are thought to be acceptable as a hypo-allergenic rice for a portion of patients with rice allergies.

\section{Conclusions}

We identified a glucosidase family as novel rice HMW allergens. We successfully generated transgenic rice with reduced content of the major and the HMW allergens, which showed reduced IgE binding to sera of a portion of rice allergy patients who are allergic to proteins other than the major allergens. These transgenic rice are thought to be an option for a portion of allergy patients with hypersensitive responses to various kinds of rice allergens.

\section{Methods}

\section{SDS-PAGE and Western blot for identification of HMW}

\section{allergens}

Seed proteins (the albumin-globulin fraction) were extracted from rice seeds (Oryza sativa cv. Koshihikari), as described previously (Wakasa et al., 2011a). The extracted proteins were separated by SDS-PAGE (10\% acrylamide), followed by Western blot using the serum IgE from individual patients, as described previously (Usui et al., 2001; Hirano et al., 2013). Protein bands bound with IgE were immunologically detected with peroxidase-labeled antihuman IgE antibody (Nordic immunological Laboratories, Susteren, Netherlands) and a chemiluminescence detection kit (GE Healthcare Biosciences, Piscataway, NJ, USA).

\section{Patient serum samples}

Blood was collected from patients with suspected allergic disorders including food allergy under medical treatment at the Hospital of Fujita Health University. Informed consent was obtained from the patients or guardians of infants or child subjects. Serum specimens were prepared from fresh blood and kept as $50 \%$ glycerol mixture at $-30^{\circ} \mathrm{C}$ until use. This study using patient serum specimens was approved by the Ethics Committee of Fujita Health University School of Medicine. Twenty-four serum specimens with relatively high IgE-binding to the rice seed albumin/ globulin fraction were selected as rice-positive specimens, whereas three specimens with relatively low IgE-binding were selected as control specimens.

\section{Protein identification by MS/MS analysis}

Protein bands detected by Coomassie brilliant blue staining were excised, in-gel digested with trypsin, and extracted according to the manufacturer's instructions. MS and MS/MS (tandem MS) analyses were performed using a MALDITOF/TOF mass spectrometer (4700 Proteomics Analyzer; Applied Biosystems, CA, USA), as described previously (Okumura et al., 2004). The obtained MS and MS/MS data were analyzed using Mascot Daemon data analysis software (Matrix Science; http://www.matrixscience.com/).

\section{Immuno-dot-blot analysis of rice seed proteins for human $\lg \mathrm{E}$}

IgE binding of patients' IgE was analyzed by dot-blotting for limited amounts of serum specimens as described previously (Wakasa et al., 2011a). Briefly, an aliquot of each rice seed extract, which was equivalent to $100 \mu \mathrm{g}$ of milled rice seeds, was spotted on a small piece of nitrocellulose membrane, blocked with gelatin solution, and then incubated with 100-fold diluted human serum specimen. The IgE bound to the rice proteins on the membrane was detected using HRP-labeled secondary antibody and a chemiluminescence HRP substrate, and the chemiluminescence intensity was quantified using NIH Image-J.

\section{Plant material and growth conditions}

Rice plants (Oryza sativa cv. Koshihikari) were grown at $25^{\circ} \mathrm{C} / 20^{\circ} \mathrm{C}(12 \mathrm{~h} / 12 \mathrm{~h}$ day/night cycles) in $12 \mathrm{~cm}$ diameter 
pots containing a commercial soil mixture (Bonsol No. 1; Sumitomo Chemicals, Osaka, Japan) with 14-14-14 chemical fertilizer. The host of the line with reduced levels of major allergens is a seed storage protein mutant named GbN-1 (cv. Koshihikari background), which lack the 26 kDa allergen (Iida et al., 1998).

\section{Vector construction}

Binary vectors were constructed for Agrobacterium-mediated transformation using the MultiSite Gateway LR clonase reaction (Invitrogen), as described previously (Wakasa et al., 2006). Briefly, gene cassettes consisting of an endospermspecific promoter [16 kDa prolamin promoter $(0.93 \mathrm{~kb})$, $13 \mathrm{kDa}$ prolamin promoter $(1.23 \mathrm{~kb})$, and $G l u B-1$ promoter $(2.4 \mathrm{~kb})]$, the inverted repeat structure of sense and antisense fragments from the coding region of ONG1-4, $52 \mathrm{kDa}$ globulin $(0.76 \mathrm{~kb})$, or $63 \mathrm{kDa}$ globulin $(0.92 \mathrm{~kb})$ separated by the rice oryzasin 1 intron $(0.99 \mathrm{~kb})$ (Asakura et al., 1995; Kuroda et al., 2010), and a terminator [16 kDa prolamin $(0.62 \mathrm{~kb})$ terminator, $13 \mathrm{kDa}$ prolamin terminator $(0.18 \mathrm{~kb})$, or $G l u B-1$ terminator $(0.6 \mathrm{~kb})]$ were inserted into the Gateway entry clones pKS221 MCS, pKS 4-1 MCS and pKS 2-3 MCS. The homologous region of ONG1 and ONG2E3 (0.72 kb), and part of ONG4 (0.7 kb) were fused and used as an inverted repeat structure of sense and antisense fragments of ONGs. These gene cassettes were introduced into pCSP mALS 43GW using MultiSite Gateway LR Clonase II Plus Enzyme Mix (Invitrogen) (Figure 2). The binary vector plasmids were introduced into the Koshihikari cv. via Agrobacterium-mediated transformation, as described previously (Wakasa et al., 2007).

\section{Protein extraction and Western blot analysis of the reduced allergen rice}

Total protein extraction and Western blot were performed as described previously (Wakasa et al., 2011a). Antibodies to $26 \mathrm{kDa}, 33 \mathrm{kDa}$, and $14-16 \mathrm{kDa}$ allergens, glutelins (GluA, GluB, and GluC), RM1, RM2, RM4, RM9, 16 kDa prolamin, $10 \mathrm{kDa}$ prolamin, OsBiP1, OsPDIL1;1, and calnexin were previously prepared in our laboratory (Takagi et al., 2006, Yasuda et al., 2009; Wakasa et al., 2011a, 2011b). The $\mathrm{MH}_{2}$-RRGEREEEDERRRHG -OH and $\mathrm{MH}_{2}-$ SGEDRRRETSLRRC -OH peptides derived from $52 \mathrm{kDa}$ (Os03g0793700) and 63 kDa (Os03g0663800) allergens, respectively, were synthesized and used to raise anti-52 and $63 \mathrm{kDa}$ allergens polyclonal antibody in a rabbit (Scrum Inc., Tokyo, Japan). Seed protein content was measured by an RC DC protein assay kit (Bio-Rad), as described in the manufacturer's protocol.

\section{RNA preparation and real-time PCR}

Total RNA was prepared from mature seeds of NT and transgenic rice plants, as described previously (Yasuda et al., 2005). Then, cDNA was synthesized from $500 \mathrm{ng}$ of total RNA using ReverTra Ace qPCR RT Master Mix with gDNA Remover (TOYOBO, Osaka, Japan), according to the manufacturer's instructions. Real-time PCR was performed using SYBR Premix Ex Taq (TaKaRa; http://www.takara-bio.com). Primer pairs for amplification were as follows: for ONG1, (5'-ACTCCATCAACACC ATGCTC-3' and 5'- CGGTGCCGATCGCCGAGTGA-3'); for ONG2E3, (5'-GGCCATTAGCATCGCAAGCT-3' and 5'-CCTCATCCACCAGGAATGCC-3'); and for ONG4, (5'GGATCGACGAGGTGAGGAGG-3' and 5'-TCCCACCTG GTGTTCGTCAG-3'). Ubiquitin (Os06g0681400) was amplified as an internal reference using the primer set (5'-GT GGTGGCCAGTAAGTCCTC-3' and 5'-GGACACAATG ATTAGGGATCA-3').

\section{Application of RiceXpro}

To investigate expression levels of the HMW rice allergens in endosperm and embryo (Additional file 1: Figure $\mathrm{S} 1$ ), we utilized the low expression-level data of reproductive organs (inflorescence, anther, pistil, ovary, embryo, and endosperm) of RiceXpro (Sato et al., 2011). The signal intensity was normalized by the 75 th percentile. The signal intensity represented in the bar graphs shows the average of three biological replicates \pm SD. The signal intensity of each gene was calculated as follows: (Row signal intensity/ 75 th percentile of each array) $\times 2,725$. The average of the 75 th percentiles from all of the arrays was 2,725 .

\section{Additional file}

Additional file 1: Figure S1. Expression of the HMW allergens in rice seeds. Expression levels of the HMW allergens during seed maturation stage (7 to 42 days after flowering) in endosperm and embryo were investigated by RiceXpro. Error bars represent standard deviation $(n=3)$.

\section{Competing interests}

The authors declare that they have no competing interests.

\section{Authors' contributions}

$\mathrm{YO}, \mathrm{YW}$, and FT designed the research and $\mathrm{YO}$ wrote the paper. $\mathrm{KH}, \mathrm{AU}$ and TM identified novel allergens. YO and YW generated transgenic rice and carried out experiments with transgenic rice. All authors read and approved the final manuscript.

\section{Acknowledgments}

We thank Ms. Y. Ikemoto, K. Miyashita, Y. Suzuki, M. Utsuno, and Y. Yajima for technical assistance. This work was supported by research grant from the Ministry of Agriculture, Forest, and Fisheries of Japan (Genomics and Agricultural Innovation no. GMC0006 to F.T and T.M.).

\section{Author details}

${ }^{1}$ Transgenic Crop Research and Development Center, National Institute of Agrobiological Sciences, Kannondai 3-1-3, Tsukuba, Ibaraki 305-8604, Japan. ${ }^{2}$ Graduate School of Bioagricultural Sciences, Nagoya University, Nagoya, Aichi 464-8601, Japan. ${ }^{3}$ Department of Pediatrics, Fujita Health University, The Second Teaching Hospital, Nakagawa-ku, Nagoya, Aichi 454-8509, Japan. 
Received: 1 May 2014 Accepted: 31 July 2014

Published online: 29 August 2014

\section{References}

Alvarez AM, Adachi T, Nakase M, Aoki N, Nakamura R, Matsuda T (1995) Classification of rice allergenic protein CDNAs belonging to the a-amylase/ trypsin inhibitor gene family. Biochim Biophys Acta 1251:201-204

Asakura T, Watanabe H, Abe K, Arai S (1995) Rice aspartic proteinase, oryzasin, expressed during seed ripening and germination, has a gene organization distinct from those of animal and microbial aspartic proteinases. Eur J Biochem 232:77-83

Gruber CW, Cemazar M, Heras B, Martin JL, Craik DJ (2006) Protein disulfide isomerase: the structure of oxidative folding. Trends Biochem Sci 31:455-464

Han X, Wang Y, Liu X, Jiang L, Ren Y, Liu F, Peng C, Li J, Jin X, Wu F, Wang J, Guo X, Zhang X, Cheng Z, Wan J (2012) The failure to express a protein disulphide isomerase-like protein results in a floury endosperm and an endoplasmic reticulum stress response in rice. J Exp Bot 63:121-130

Hirano K, Hino S, Oshima K, Okajima T, Nadano D, Urisu A, Takaiwa F, Matsuda T (2013) Allergenic potential of rice-pollen proteins: expression, immuno-cross reactivity and IgE-binding.J Biochem 154:195-205

Hoffman DR (1975) The specificities of human IgE antibodies combining with cereal grains. Immunochemistry 12:535-538

Houston NL, Fan C, Xiang JQ, Schulze JM, Jung R, Boston RS (2005) Phylogenetic analyses identify 10 classes of the protein disulfide isomerase family in plants, including single-domain protein disulfide isomerase-related proteins. Plant Physiol 137:762-778

lida S et al (1998) Rice mutant lines lacking a-globulin. Breed Sci 48:45-49

Ikezawa Z et al (1992) A probable involvement of rice allergy in severe type of atopic dermatitis in Japan. Acta Derm Venereol Suppl (Stockh) 176:103-107

Kato T, Miyahara K, Nishino T (2000) Release of allergenic proteins from rice grains induced by high hydrostatic pressure. J Agric Food Chem 48:3124-3129

Kuroda M, Kimizu M, Mikami C (2010) A simple set of plasmids for the production of transgenic plant. Biosci Biotechnol Biochem 74:2348-2351

Limas GG, Salinas M, Moneo I, Fischer S, Wittmann-Liebold B, Méndez E (1990) Purification and characterization of ten new rice $\mathrm{NaCl}$-soluble proteins: identification of four protein-synthesis inhibitors and two immunoglobulin binding proteins. Planta 181:1-9

Matsuda T, Nakasa M, Alvarez AM, Izumi H, Kato T, Tada Y (2006) Rice-seed allergenic protein and hypoallergenic rice. In: Mine Y, Shahidi F (eds) In Nutraceutical Proteins and Peptides in Health and Disease. Taylor \& Francis Group, London, pp 493-511

Mehr SS, Kakakios AM, Kemp AS (2009) Rice: a common and severe cause of food protein-induced enterocolitis syndrome. Arch Dis Child 94:220-223

Nakai H, Ito T, Hayashi M, Kamiya K, Yamamoto T, Matsubara K, Kim YM, Jintanart W, Okuyama M, Mori H, Chiba S, Sano Y, Kimura A (2007) Multiple forms of alpha-glucosidase in rice seeds (Oryza sativa L., var Nipponbare). Biochimie 89:49-62

Okumura H, Kohno Y, Iwata Y, Mori H, Aoki N, Sato C, Kitajima K, Nadano D, Matsuda T (2004) A newly identified zona pellucida glycoprotein, ZPD, and dimeric ZP1 of chicken egg envelope are involved in sperm activation on sperm-egg interaction. Biochem J 384:191-199

Oono Y, Wakasa Y, Hirose S, Yang L, Sakuta C, Takaiwa F (2010) Analysis of ER stress in developing rice endosperm accumulating beta-amyloid peptide. Plant Biotechnol J 8:691-718

Sato Y, Antonio BA, Namiki N, Takehisa H, Minami H, Kamatsuki K, Sugimoto K, Shimizu Y, Hirochika H, Nagamura Y (2011) RiceXPro: a platform for monitoring gene expression in japonica rice grown under natural field conditions. Nucleic Acids Res 39:D1141-1148

Satoh R, Nakamura R, Komatsu A, Oshima M, Teshima R (2011) Proteomic analysis of known and candidate rice allergens between non-transgenic and transgenic plants. Regul Toxicol Pharmacol 59:437-444

Satoh-Cruz M, Crofts AJ, Takemoto-Kuno Y, Sugino A, Washida H, Crofts N, Okita TW, Ogawa M, Satoh H, Kumamaru T (2010) Protein disulfide isomerase like 1-1 participates in the maturation of proglutelin within the endoplasmic reticulum in rice endosperm. Plant Cell Physiol 51:1581-1593

Shibasaki M, Suzuki S, Nemoto H, Kuroume T (1979) Allergenicity and lymphocyte-stimulating property of rice protein. J Allergy Clin Immunol 64:259-265

Sicherer SH, Eigenmann PA, Sampson HA (1998) Clinical features of food protein-induced enterocolitis syndrome. J Pediatr 133:214-219
Takagi H, Hirose S, Yasuda H, Takaiwa F (2006) Biochemical safety evaluation of transgenic rice seeds expressing $T$ cell epitopes of Japanese cedar pollen allergens. J Agric Food Chem 54:9901-9905

Uchio E, Miyakawa K, Ikezawa Z, Ohno S (1998) Systemic and local immunological features of atopic dermatitis patients with ocular complications. Br J Ophthalmol 82:82-87

Urisu A, Yamada K, Masuda S, Komada H, Wada E, Kondo Y, Horiba F, Tsuruta M, Yasaki T, Yamada M, Torii S, Nakamura R (1991) 16-kilodalton rice protein is one of the major allergens in rice grain extract and responsible for cross-allergenicity between cereal grains in the poaceae family. Int Arch Allergy Appl Immunol 96:244-252

Usui Y, Nakase M, Hotta H, Urisu A, Aoki N, Kitajima K, Matsuda T (2001) A 33-kDa allergen from rice (Oryza sativa L.). cDNA cloning, expression, and identification as a novel glyoxalase I. J Biol Chem 276:11376-11381

Wakasa Y, Yasuda H, Takaiwa F (2006) High accumulation of bioactive peptide in transgenic rice seeds by expression of introduced multiple genes. Plant Biotechnol J 4:499-510

Wakasa Y, Ozawa K, Takaiwa F (2007) Agrobacterium-mediated transformation of a low glutelin mutant of 'Koshihikari' rice variety using the mutatedacetolactate synthase gene derived from rice genome as a selectable marker. Plant Cell Rep 26:1567-1573

Wakasa Y, Hirano K, Urisu A, Matsuda T, Takaiwa F (2011a) Generation of transgenic rice lines with reduced contents of multiple potential allergens using a null mutant in combination with an RNA silencing method. Plant Cell Physiol 52:2190-2199

Wakasa Y, Yasuda H, Oono Y, Kawakatsu T, Hirose S, Takahashi H, Hayashi S, Yang L, Takaiwa F (2011b) Expression of ER qualitycontrol related genes in response to changes in BiP1 levels in developing rice endosperm. Plant J 65:675-689

Watanabe M, Miyakawa J, Ikezawa Z, Suzuki Y, Hirano T, Yoshizawa T, Arai S (1990a) Production of hypoallergenic rice by enzymatic decomposition of constituent proteins. J Food Sci 55:781-783

Watanabe M, Yoshizawa T, Miyakawa J, Ikezawa Z, Abe K, Yanagisawa T, Arai S (1990b) Quality improvement and evaluation of hypoallergenic rice grains. J Food Sci 55:1105-1107

Wilkinson B, Gilbert HF (2004) Protein disulfide isomerase. Biochim Biophys Acta 1699:35-44

Yasuda H, Tada Y, Hayashi Y, Jomori T, Takaiwa F (2005) Expression of the small peptide GLP-1 in transgenic plants. Transgenic Res 14:677-684

Yasuda H, Hirose S, Kawakatsu T, Wakasa Y, Takaiwa F (2009) Overexpression of BiP has inhibitory effects on the accumulation of seed storage proteins in endosperm cells of rice. Plant Cell Physiol 50:1532-1543

\section{doi:10.1186/s12284-014-0019-0}

Cite this article as: Ogo et al:: Generation of transgenic rice with reduced content of major and novel high molecular weight allergens. Rice 2014 7:19.

\section{Submit your manuscript to a SpringerOpen ${ }^{\circ}$ journal and benefit from:}

- Convenient online submission

- Rigorous peer review

- Immediate publication on acceptance

- Open access: articles freely available online

- High visibility within the field

- Retaining the copyright to your article

Submit your next manuscript at $>$ springeropen.com 